\title{
EAl Endorsed Transactions

\section{Design and Comparison of Performance of DFIG Based Wind Turbine with PID Controller, Fuzzy Controller, Artificial Neural Network and Model Predictive Controller}

\author{
K. Naresh ${ }^{1, *}$, P. Umapathi Reddy ${ }^{2}$, P. Sujatha ${ }^{3}$
}

${ }^{1}$ Research Scholar, EEE Department, JNTUA Ananthapuramu, Ananthapuramu, Andhra Pradesh- India- 515002

${ }^{2}$ Professor, EEE Department, SVEC- Thirupati, Andhra Pradesh- India- 517102

${ }^{3}$ Professor, EEE Department, JNTUA Ananthapuramu, Ananthapuramu, Andhra Pradesh-India- 515002

\begin{abstract}
The everyday benefits of environmentally friendly power sources urges to build their use to the bigger degree of which wind energy is the most accessible asset. This paper presents the plan of multimode hang control methodology based variable speed wind power age framework. The multimode hang control procedure improves the framework to work regarding the network framework and furthermore in the independent method of activity. The multimode control methodology utilizes the DC connect voltage regulator to control the DC interface capacitor voltage for working the framework side converter and current regulator to control current and force of the rotor side converter. The control methodology is investigated with the customary regulator like PI regulator, astute regulators like Fuzzy regulator, fake neural organization (ANN) and model prescient regulator (MPC) which predicts the future factors. A correlation has been performed with the previously mentioned various sorts of regulators based breeze power age framework regarding various boundaries. This paper likewise includes examination of various experiments with the previously mentioned regulators. The examination of various experiments with various regulators has been performed utilizing MATLAB 2013a and every one of the outcomes are checked.
\end{abstract}

Keywords: Multimode control strategy, PI controller, Fuzzy controller, Artificial neural network, Model predictive controller.

Received on 30 April 2021, accepted on 18 June 2021, published on 29 June 2021

Copyright (C) 2021 K. Naresh et al., licensed to EAI. This is an open access article distributed under the terms of the Creative Commons Attribution license, which permits unlimited use, distribution and reproduction in any medium so long as the original work is properly cited.

doi: 10.4108/eai.29-6-2021.170251

*Corresponding author. Email: Naresh5kelothu@gmail.com

\section{Introduction}

Even in these days there are many rural areas which are not in connection with the grid and lack of electricity, power quality problems. To overcome these problems, generators or UPS systems can be a solution for the power interruption problems [1-3]. But usage of generators may not be a superior solution as they cause pollution, high cost, maintenance, lack of continuity. To overcome the dependency on the above mentioned solution, a renewable energy source is the best option where the availability of source is unlimited, no harmful effects.

Wind energy systems are classified as fixed speed wind energy systems and variable speed wind energy systems. But the fixed speed wind energy systems have disadvantage of fixed speed throughout the operation, uncontrollability of power of the system. To avoid this problem, variable speed wind energy systems have been chosen which have the capability to operate over the wide 
range of speeds and full control of power. Among the variable speed wind energy systems, doubly fed induction generator based wind energy systems [5-7] have been chosen due to their robust construction, low maintenance, simplicity but the disadvantage with the renewable energy source is lack of controllability and non availability of wind all the times of a day. To avoid interruption of the supply irrespective of wind speeds, energy storage system

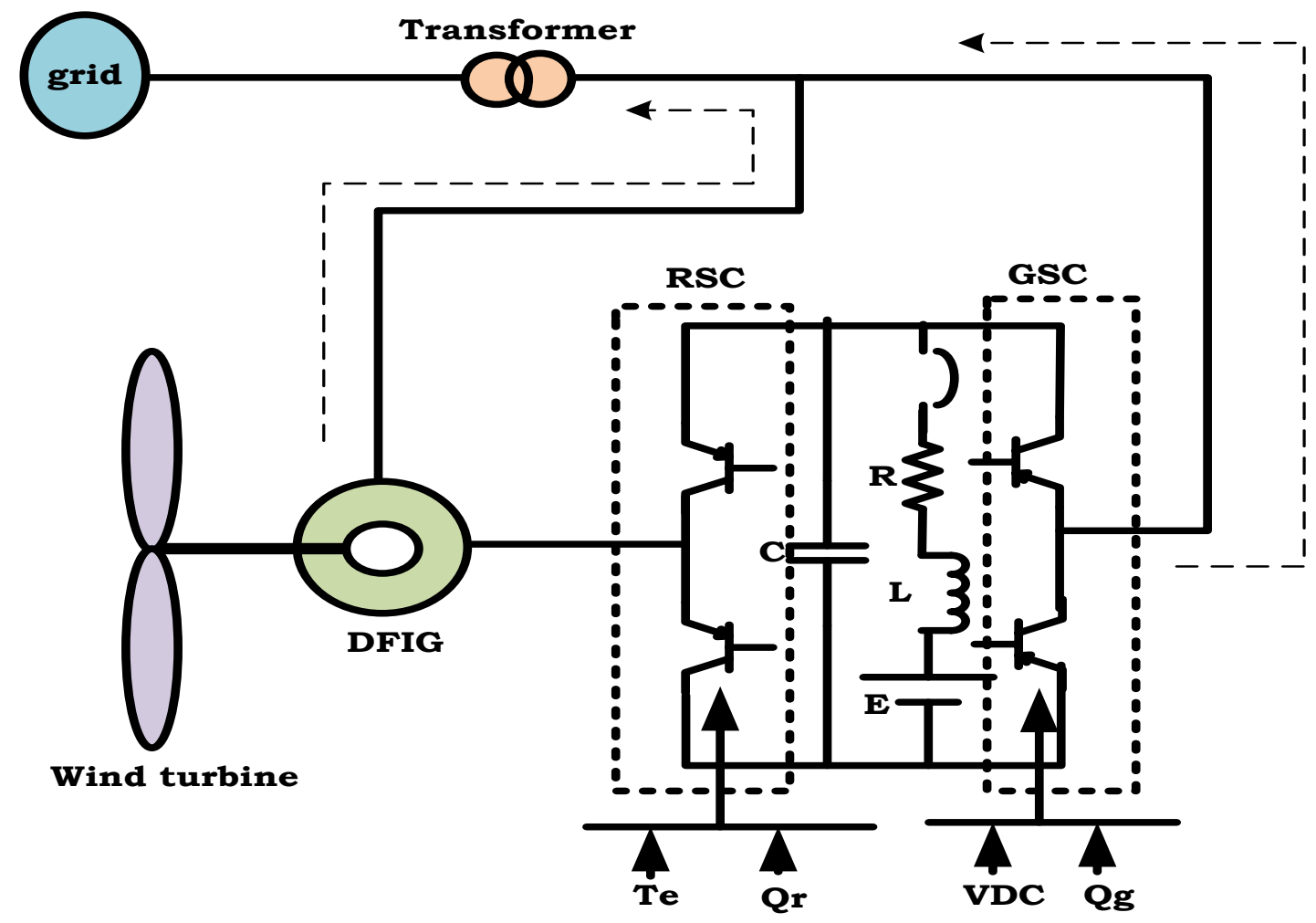

Figure 1. Block diagram representation of proposed wind energy system

have been incorporated into the system. There have been number of energy storage systems based on hydrogen, UPS batteries, SMES, Flywheel energy storage system. But the above broached energy storage system [9] suffers from the problems of high cost, maintenance. To design the system with low price storage systems, DC link capacitor, battery have been chosen for energy storage.

As the full range of wind speed may not be constant all the day, a control strategy has to be used to control the system and storage devices. A multimode control strategy has been incorporated into the system [10-13] where the system can be operated with the grid or with the disconnection of grid in case of grid failure and also the system can be operated with battery or without battery. The proposed control strategy enables the system to operate in grid connected mode with the regulation of power, DC link voltage and in islanded mode with the regulation of frequency and voltage. The regulation is based on active power-frequency, reactive power voltage regulation technique. The control strategy is based on current and voltage control strategy with PID controller. The same control strategy is performed with fuzzy logic controller [15-17] and also analysed with the neural network with input, hidden and output layers. A new model prediction controller has been replaced with the above mentioned controllers and designed to absorb the past, present values, reference values and predict the future values to provide efficient controlling over the system parameters [21-23]. The proposed system is also made to operate in parallel with other wind power generation units, solar generation units, and different types of loads like RL load, induction motor load [24] and FACTS device like D-STATCOM.

The paper is organized as follows: Section I presents introduction to the proposed system, Section II presents the block diagram model of the proposed system with different controllers and their mathematical modelling. Section III deals with the discussion of simulation work and results. Section IV conclusions drawn from the proposed work.

\section{Block Diagram Representation of the Proposed System}

The square graph of the proposed is appeared in figure 1 where the principle unit comprises of wind turbine, doubly took care of enlistment generator (DFIG), consecutive associated two voltage source converters, transformer. The DFIG wind energy framework is associated at the mark of basic coupling through the interface transformer. The DFIG stator is 
straightforwardly associated with the network through interface transformer and rotor is associated with the transformer through AC-DC-AC converter. The AC-DC$\mathrm{AC}$ converter consists of two voltage source converters, they are rotor side converter whose information is gotten from the rotor windings and the yield is taken care of to the DC connect capacitor, matrix side converter whose info is acquired from the capacitor and yield is taken care of at point of normal coupling. A battery has been associated in corresponding with the DC interface capacitor through a breaker. An inductor has been associated in arrangement with the battery to diminish swells through the battery current and a resistor has been associated with incorporate ohmic misfortunes of the battery where the battery is addressed with the voltage source.

\section{Distribution Network Representation of the Proposed System}

The figure 2 illustrates the single line diagram of the proposed system in connection with the other parallel units through the breakers. The grid has been represented with an AC voltage source and the distribution system has been represented with the resistance and inductance. The distribution system can be disconnected from the proposed system with the breaker $\left(B_{g}\right)$. The below figure also shows the parallel connection of other units like RL load, induction motor load through the breakers $\left(B_{L}, B_{I M}\right)$.
The constant speed wind energy unit has been connected through the breaker $\left(B_{I G}\right)$ and PMSG based wind energy unit has been connected through the breaker $\left(B_{P M S G}\right)$. The facts device D-STATCOM has been connected through the breaker $\left(B_{F}\right)$ and solar unit has been connected through the breaker $\left(B_{S}\right)$.

\section{Control Strategy}

\section{(i). Rotor Side Control (RSC) Strategy}

The equation for the torque of the DFIG in terms of speed can be given as

$$
T_{e}=K w_{r}^{2}
$$

The constant $\mathrm{K}$ can be given as

$$
K=\frac{1}{2} \frac{\mathrm{p} A r^{3} C_{p}}{N^{3} \lambda^{3}}
$$

where $C_{p}$ is power coefficient of wind turbine, $A$ is area of the turbine, $\mathrm{N}$ is the speed of the turbine, $\lambda$ is the tip speed ratio, $p$ is the air density.

From the basic of power- torque relationship, the equation for the power generated can be given as

$$
P_{e}=K w_{r}^{3}
$$

The torque equation from the stator flux coordinates can be given as

$$
T_{e}=\frac{V}{(1+€) w} i_{r d}
$$




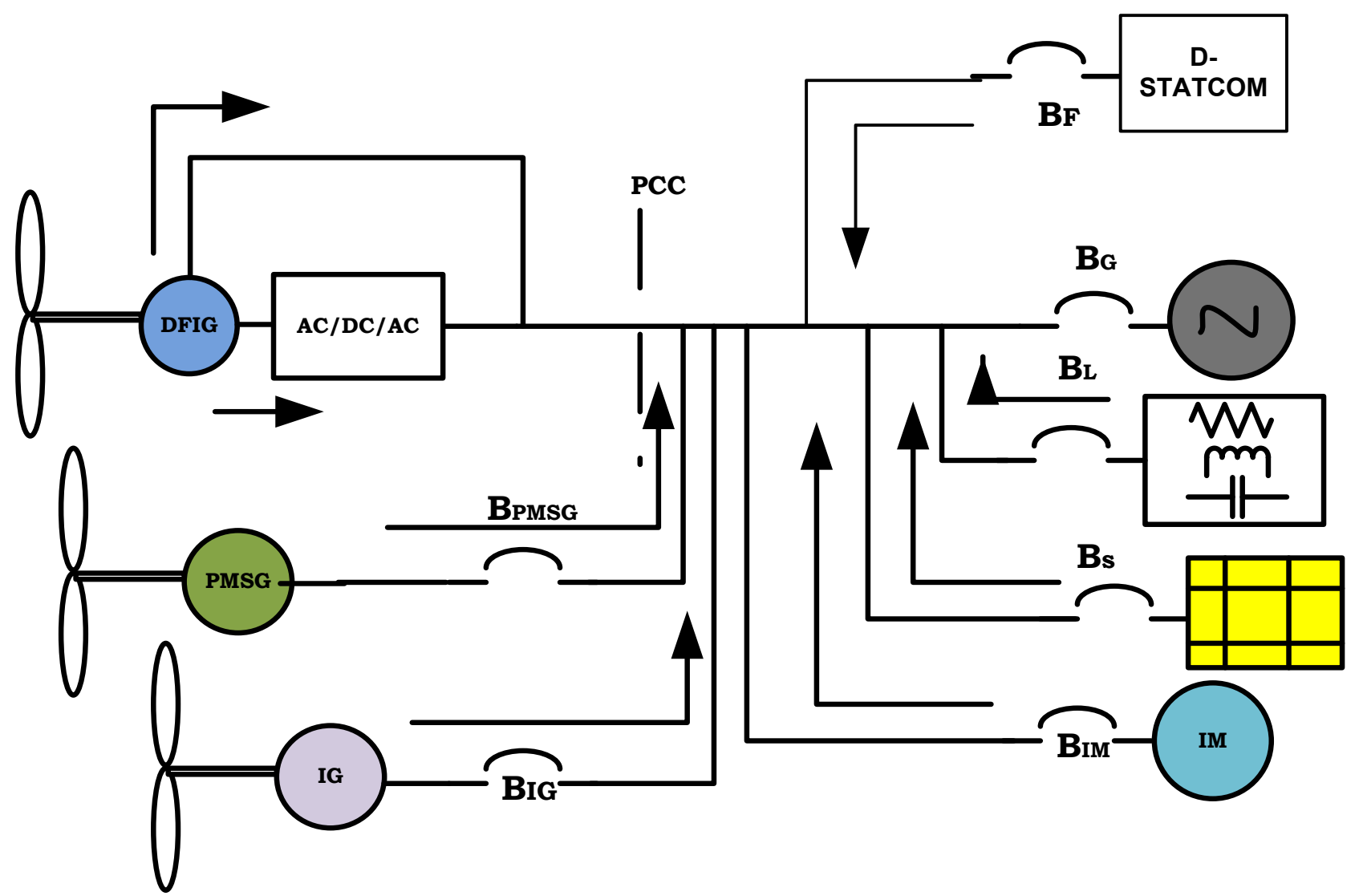

Figure 2. Distribution network diagram of the proposed system

Then the reference current in order to maximise the power can be given as

$$
i_{r d}=\frac{(1+€) w}{V} T_{e}
$$

The reactive power control can be obtained from the following equation as

$$
Q=\frac{V^{2}}{(1+€) w L_{m}}-\frac{V}{(1+€)} i_{r d}
$$

\section{(ii). Grid Side Control (GSC) Strategy}

In the framework associated mode, the control procedure has been empowered to control the DC interface voltage and to direct the conveyed genuine force and in the islanded mode the control methodology has been empowered to control the organization recurrence and voltage of the framework.

The DC voltage is controlled dependent on the accompanying condition

$$
P_{g}-P_{r}=\frac{1}{2} c \ddot{V}_{c}
$$

Where $P_{g}$ is the power of GSC, $P_{r}$ is the power of RSC.

The current controlling will be performed from the DC link voltage controlling with PID controller whose block diagram is shown in figure 3.

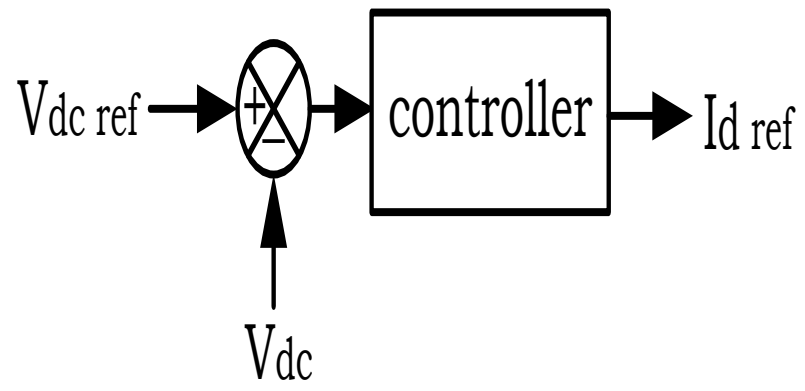

Figure 3. DC link voltage controller

The d-axis reference current is obtained from the DC link voltage controller where the q-axis reference current is obtained from the reactive power variable of the grid side converter whose equation is given as

$$
I_{q \text { ref }}=T Q_{g s c}
$$

\section{Controllers Used in the DC Link Voltage Controller}

(i). Proportional Integral Derivative (PID) controller Controller is a device which controls the system actual output based on the reference output value. It tracks the reference and minimizes the error between the actual output and the reference output values either by increasing or decreasing the control inputs to the system so that the system variable moves closer to the reference value. PID controller is a proportional integral derivative 
controller which controls the past, present values over the period of time. It reduces the transient response and also reduces steady state error.

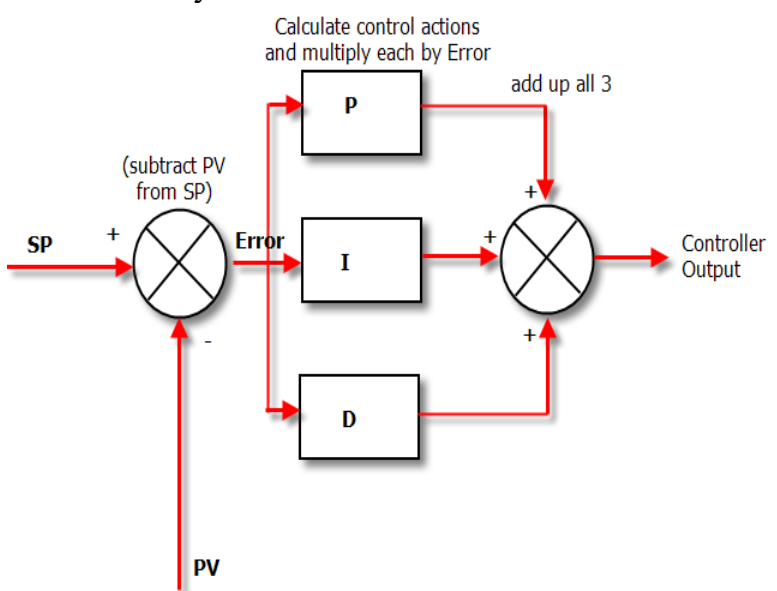

Figure 4. Block diagram of PID controller

The controller consists of three variable namely proportional variable $K_{p}$, integral variable $K_{i}$, derivative variable $K_{d}$. The proportional variable improves the rise time, integral variable improves the overshoot, derivative variable eliminates the steady state error. The total sum of the proportional-integral-derivative variables constitutes PID controller whose block diagram is shown below. The gains of $K_{p}, K_{i}, K_{d}$ have been tuned to attain the required output with fast dynamic response.

The equation for the output response from the controller can be given as

$y(t)=K_{p} e(t)+K_{i} \int e(t) d t+K_{d} \frac{d e(t)}{d t}$

\section{(ii). Fuzzy Controller}

Fuzzy controller is an intelligent controller which provides fast, dynamic response with zero steady state error. It is a digital controller which provides better response compared to the classical analog controllers. It is based on the expert information and knowledge based system. It tries to minimize the error between the actual value and the reference value. Generally two inputs namely error and change in error are given as inputs to the controller in terms of membership functions and the output of the controller is also in terms of membership function. The block diagram of fuzzy logic controller based DC link voltage controller is shown in figure 5.

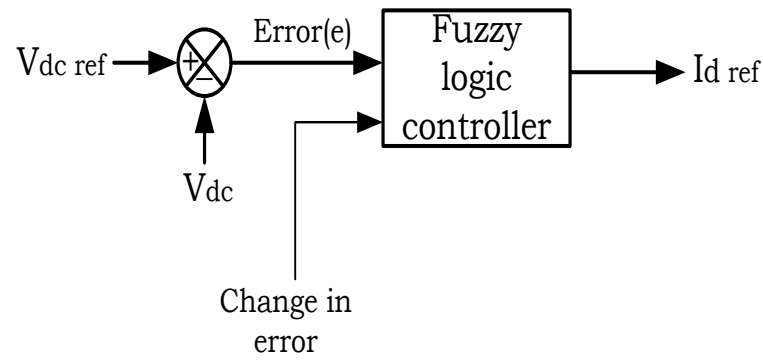

Figure 5. Fuzzy logic controller based DC link voltage controller
The error between the reference DC link voltage and the actual voltage is fed as one of the input for the fuzzy logic controller and the change in error is fed as another input. These are fed as input to fuzzifier for converting crisp variable into fuzzy variables. Then the two converted fuzzy membership functions have been analyzed with seven variables named as PB, PM, PS, ZO NS, NM, NB. Using IF-THEN rules from the rule based system, 49 rules have been designed and applied to form the output membership function. Then the fuzzy output membership function has been converted into crisp value by using centroid type of defuzzification method. The following table gives the fuzzy logic table used for the DC link voltage controller.

Table 1. Rule Based System of Fuzzy Controller

\begin{tabular}{|r|l|l|l|l|l|l|l|}
\hline e & NB & NM & NS & ZO & PS & PM & PB \\
\hline NB & NB & NB & NB & NB & NM & NS & ZO \\
\hline NM & NB & NB & NB & NM & NS & ZO & PS \\
\hline NS & NB & NB & NM & NS & ZO & PS & PM \\
\hline ZO & NB & NM & NS & ZO & PS & PM & PB \\
\hline PS & NM & NS & ZO & PS & PM & PB & PB \\
\hline PM & NS & ZO & PS & PM & PB & PB & PB \\
\hline PB & $Z O$ & PS & PM & PB & PB & PB & PB \\
\hline
\end{tabular}

(iii). Artificial Neural Network (ANN)

Artificial neural network has been one of the intelligent controller to control the output of any system and attain the required output. ANN is designed from the basics of human nervous system. All the equivalents elements of the human nervous system have been designed to process the system as of like human to achieve the fast, steady state response. ANN basically consists of inputs which are transferred through weights, then the summed up information of the weighted inputs is passed through the activation function for obtaining the output of the controller and this output is fed to the system and if error is not zero the weights are adjusted and again the process is repeated until the error becomes zero.

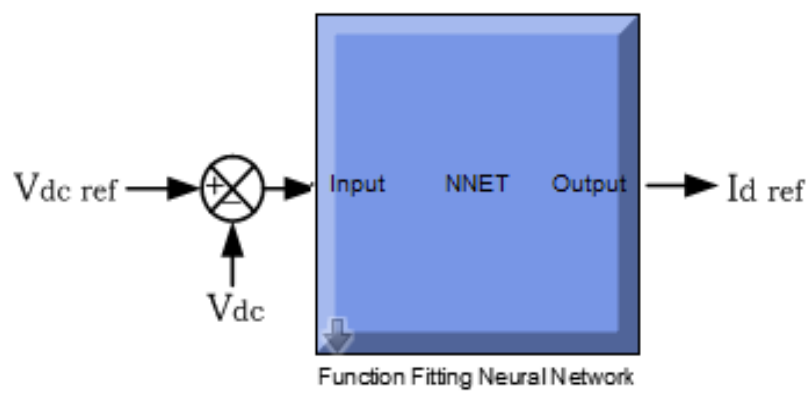

EAI Endorsed Transactions on Energy Web 112021 - 112021 | Volume 9 | Issue 37 | e6 
Figure 6. ANN based DC link voltage controller

All the inputs and weights are represented in the form of layers and so a neural network may contain more than one layer. The figure 7 shows the neural network that has been used in the proposed system which consists of input layer, one hidden layer and one output layer.

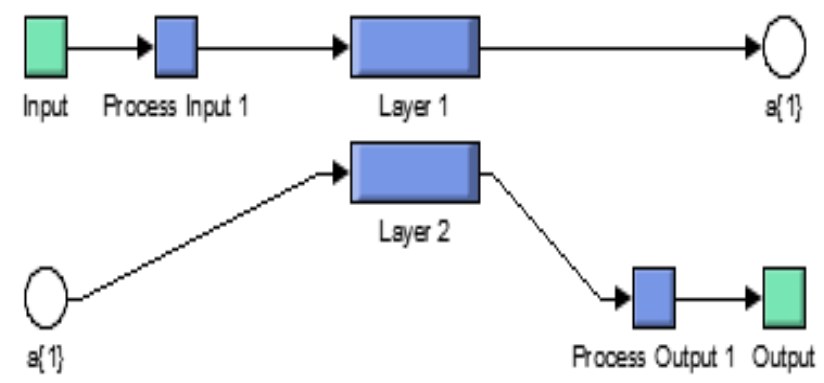

Figure 7. Internal Circuit of ANN

There are number of activation functions like linear, sigmoidal, ReLU, tangent, etc. Tangent sigmoid activation function has been used in between inputhidden layer and linear activation function has been used in between hidden-output layer.

The equations related to the above diagram can be given as

$$
\begin{aligned}
& X=\Sigma x W+b \\
& Y=f(X) \ldots \ldots .
\end{aligned}
$$

From the above equation, the sum of weighted inputs and bias are fed as an input to the tangent sigmoid activation function obtaining output at the hidden layer. At the hidden layer the above obtained output is fed as an input through the synaptic weights and again the weighted sum is passed through the linear activation function and getting an output given as d-axis current.

\section{(iv). Model Predictive Controller (MPC)}

Another controller which is used for controlling the DC link voltage of the capacitor is model predictive controller (MPC). The main characteristic of MPC is prediction of the future variables in advance and there by performing the control strategy based on the present inputs until a predefined horizon. Also an optimization has also been performed to minimize the cost function with a weight for satisfactory control of overall system. MPC consists of four variables named as measured output which is actual output of the system, measured variable which is the processed error, measured disturbance which is the error between the two variables, reference.

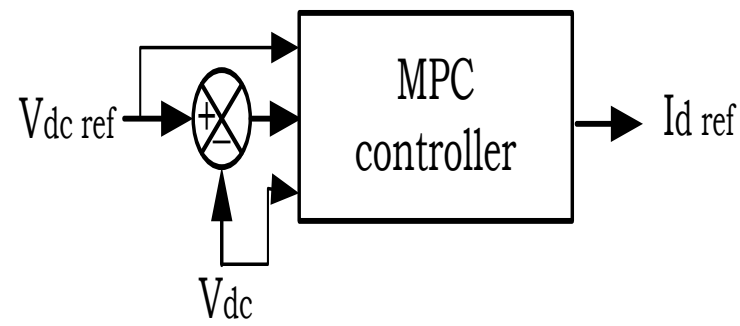

Figure 8. Model Predictive Control based DC link voltage controller

From the above block diagram, the reference value and actual values, error of DC link voltage are fed as inputs to the MPC controller, then it will process by performing the analysis of future states and the output will be obtained. The equation involving the control of DC link voltage using MPC controller can be given as

$$
\begin{aligned}
& \frac{d}{d t} V_{c}=\frac{1}{C} i_{c} \\
& V_{c}(k+1)=V_{c}(k)+i_{c}(k) T_{s}
\end{aligned}
$$

Where $V_{c}(k+1)$ is the DC link voltage of next state, $V_{c}(k)$ is the DC link voltage of present state, $i_{c}(k)$ is the current through the capacitor at present state, $T_{s}$ is the sampling time.

\section{Simulation Results}

The proposed system has been simulated using Fuzzy controller, artificial neural network, model predictive controller for different test cases.

\section{(i). Fuzzy Controller Based System}

Test Case 1: When operating system in grid connected mode with battery

This mode starts as start up of the system from $\mathrm{t}=0 \mathrm{sec}$ to $\mathrm{t}=7 \mathrm{sec}$. Initially the wind speed of $10 \mathrm{~m} / \mathrm{sec}$ is fed to the turbine from $\mathrm{t}=0 \mathrm{sec}$ to $\mathrm{t}=7 \mathrm{sec}$. 
Design and comparison of performance of DFIG based wind turbine with PID controller, FUZZY Controller, Artificial Neural Network and Model Predictive Controller

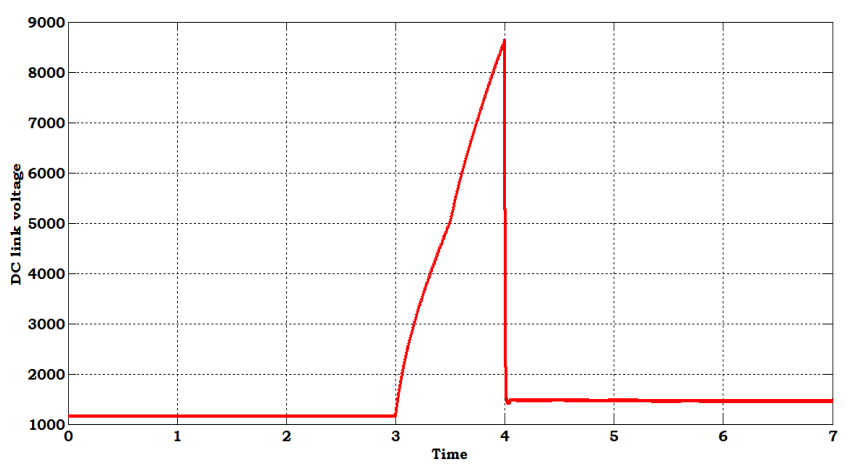

(a)

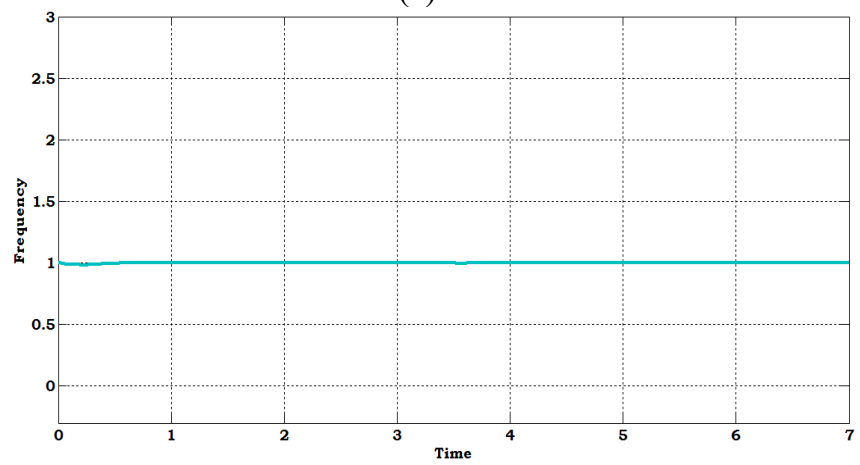

(c)

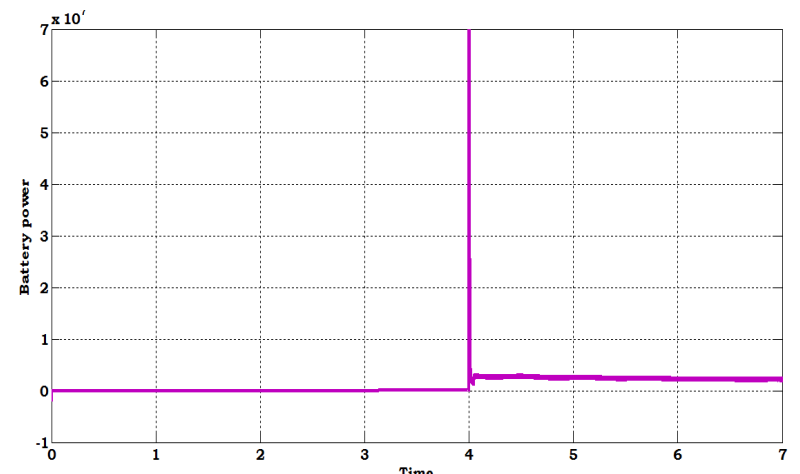

(b)

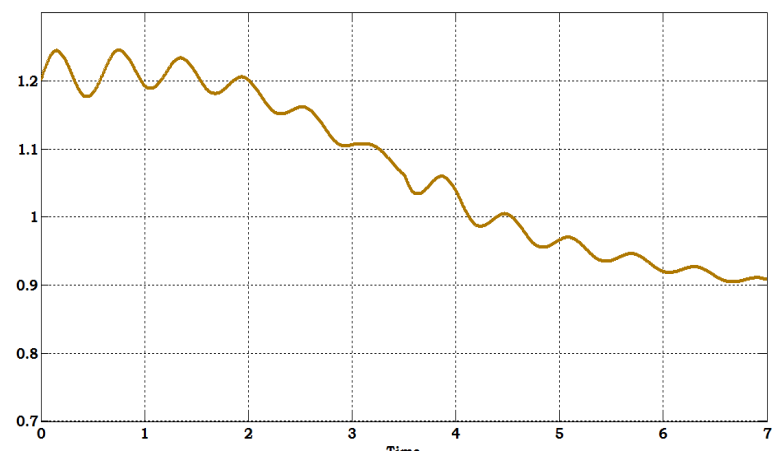

(d)

Figure 9. Waveform of(a). DC link voltage, (b). Battery Power, (c). Frequency, (d). Speed with fuzzy controller

From $\mathrm{t}=0 \mathrm{sec}$ to $\mathrm{t}=3 \mathrm{sec}$, the DC link voltage is maintained at initial capacitor voltage value. The breaker at GSC is enabled at $\mathrm{t}=3 \mathrm{sec}$, then there is sudden transient in the output, then the DC link voltage controller turns on and maintains the voltage, frequency at the reference value. The breaker at RSC is enabled at $\mathrm{t}=3.5 \mathrm{sec}$ and the battery is closed from $\mathrm{t}=4 \mathrm{sec}$ to $\mathrm{t}=7 \mathrm{sec}$ which shows there is continuous tracking action of the controllers there by maintaining frequency, speed, DC link voltage constant.

Test Case 2: When operating system in grid connected mode with sudden disconnection of battery

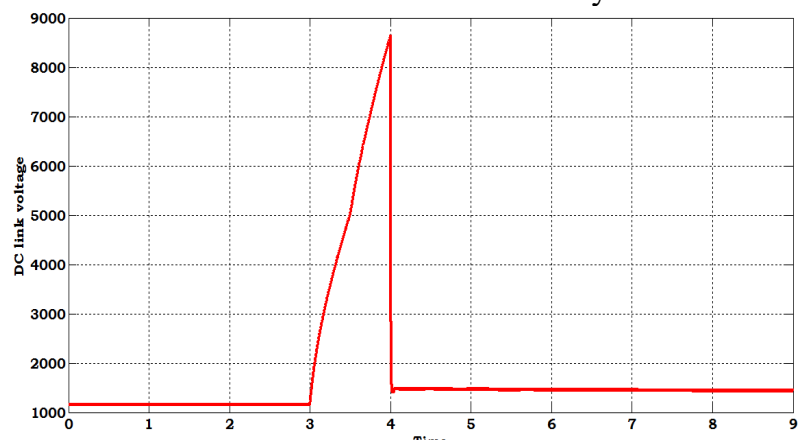

(a)

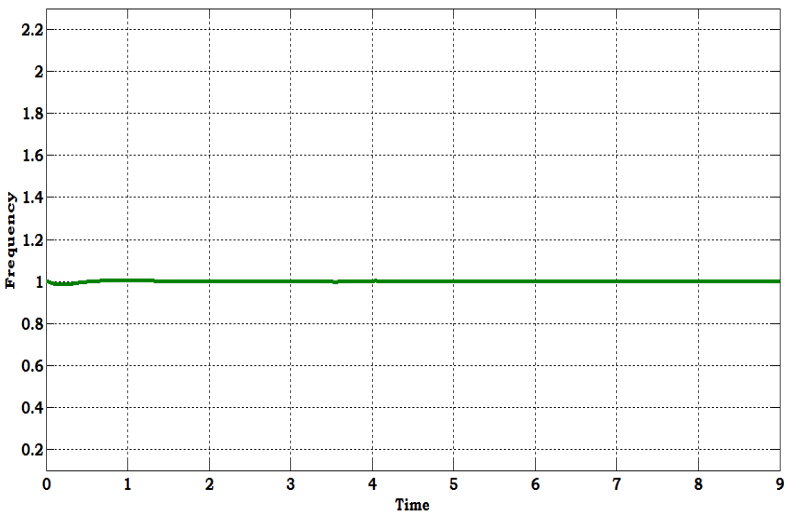

(b)

Figure 10. (a). DC link voltage, (b).Frequency There is sudden change in DC link voltage at $\mathrm{t}=3 \mathrm{sec}$ but controller brings back voltage and frequency in constant. Test Case 3: when operating system in grid connected mode with sudden connection of other units.

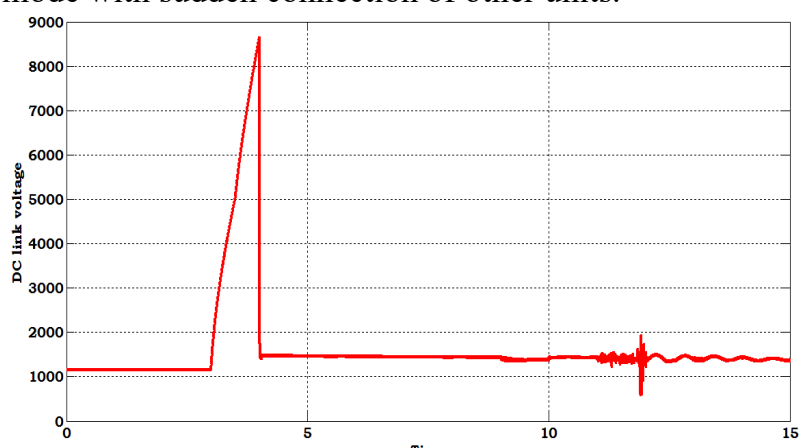

(a) 


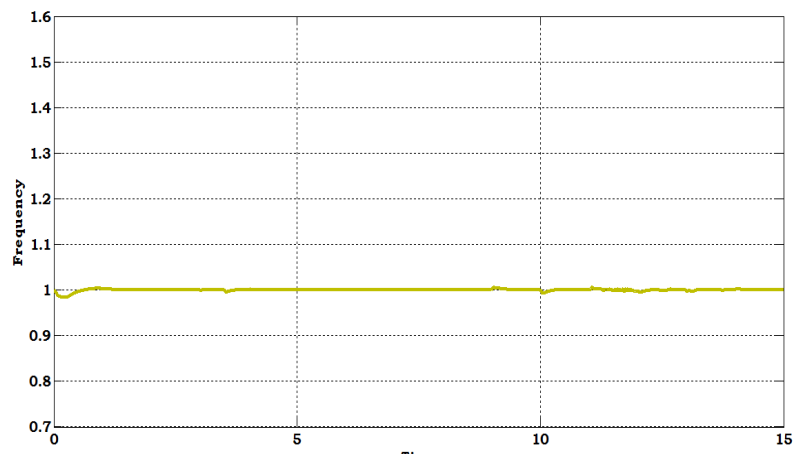

(b)

Figure 11. (a). DC link voltage, (b).Frequency

Other units are suddenly connected at $\mathrm{t}=12 \mathrm{sec}$, hence small disturbance observed in DC link voltage but controller brought back voltage in accurate constant value and frequency also maintained with in the limit perfectly. Test Case 4: When operating system in grid connected mode with sudden fault.

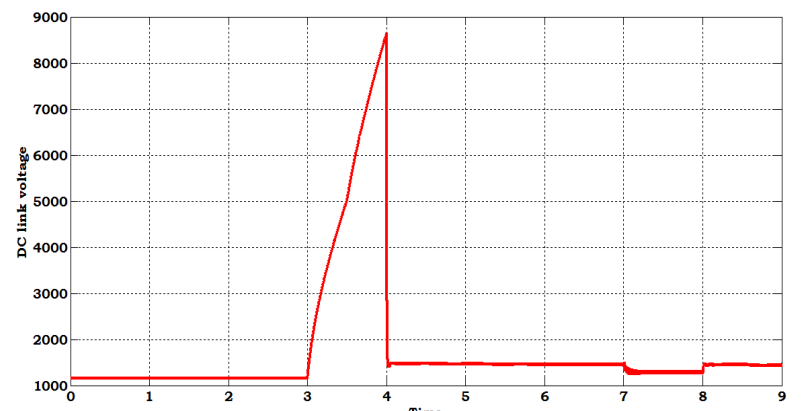

(a)

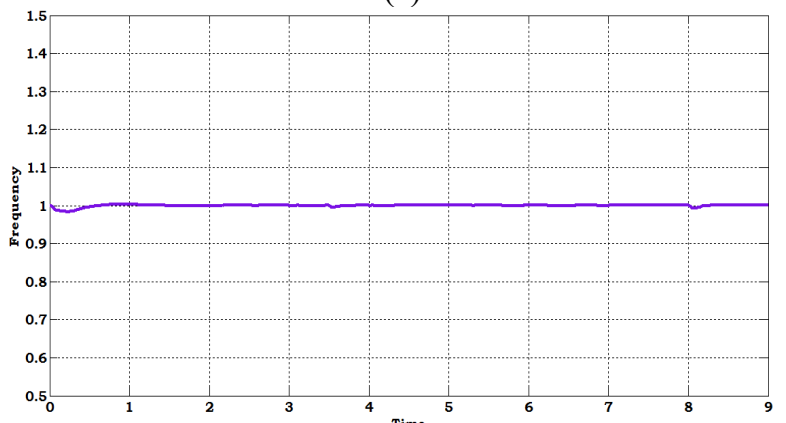

(b)

Figure 12. (a). DC link voltage, (b).Frequency Sudden transient occurred at $\mathrm{t}=3 \mathrm{sec}$ to $4 \mathrm{sec}$ and fault occurred at $\mathrm{t}=7$ sec but still fuzzy controller is maintaining constant DC link voltage and frequency.

Test Case 5: When operating system in islanded mode

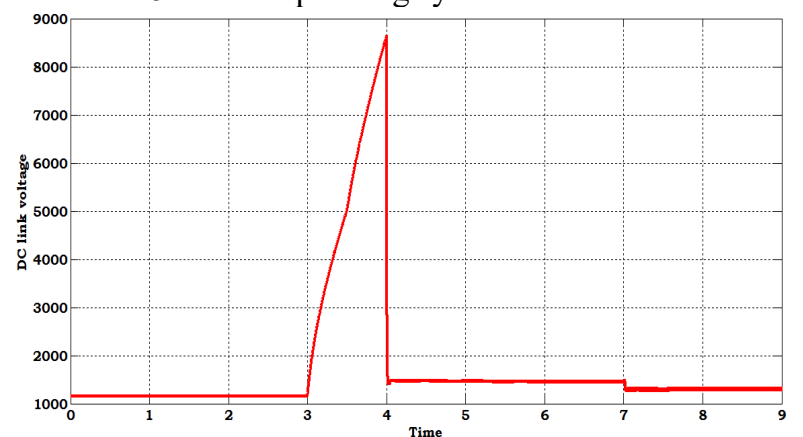

(a)

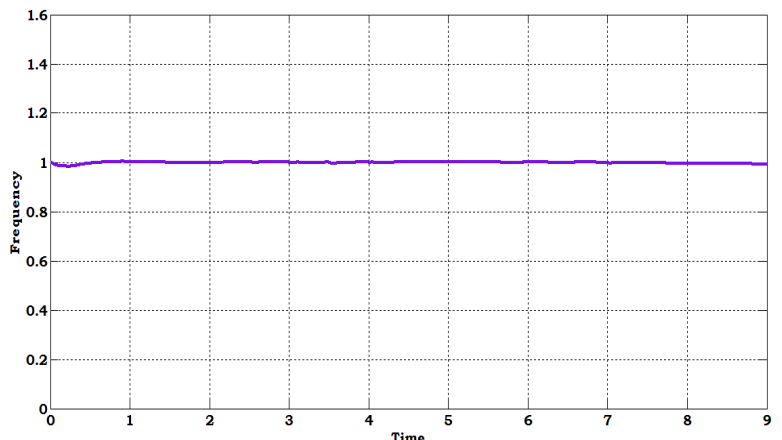

(b)

Figure 13. (a). DC link voltage, (b).Frequency

Even in islanded mode also fuzzy controller is maintaining constant DC link voltage and frequency.

Test Case 6: When operating system in islanded mode with sudden connection of other units

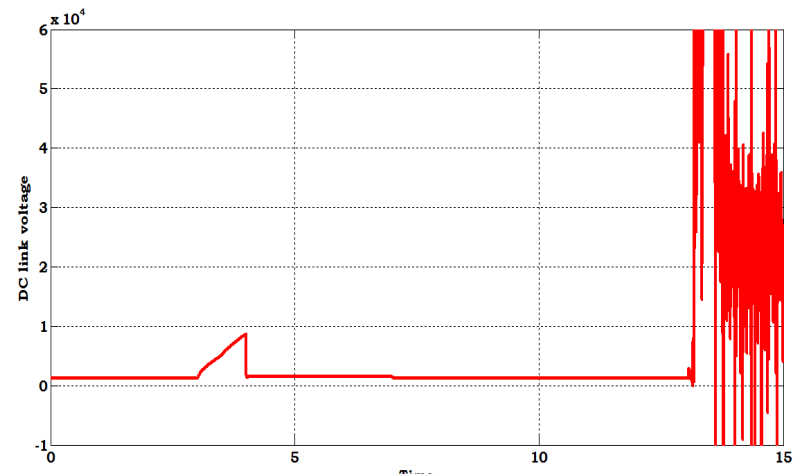

(a)

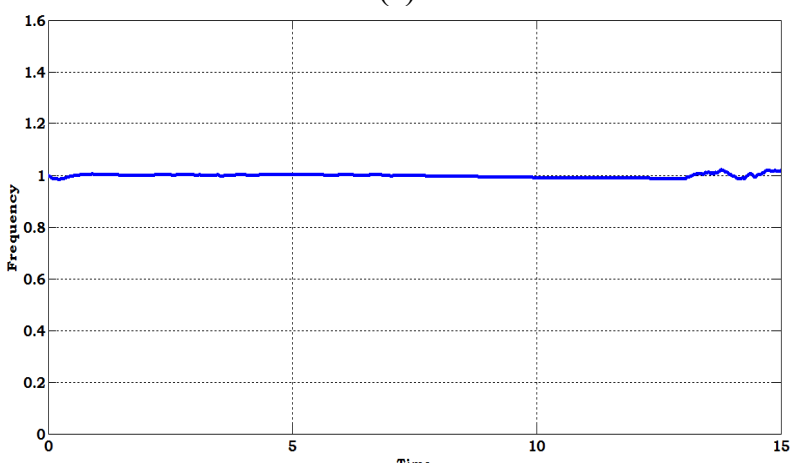

(b)

Figure 14. (a). DC link voltage, (b).Frequency

Test Case 7: When operating system in islanded mode with sudden fault

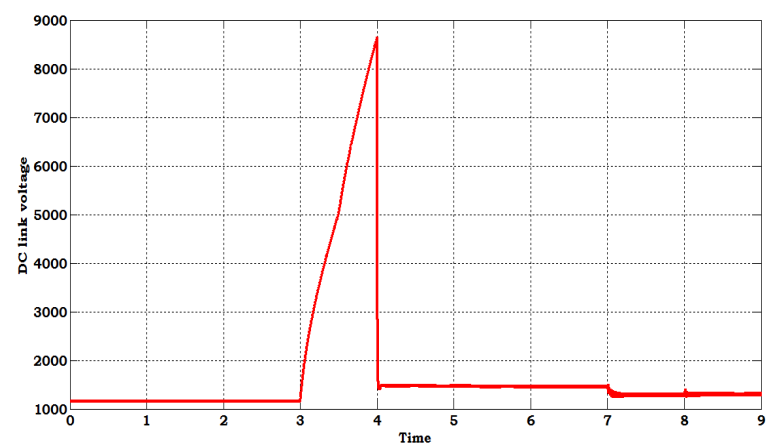

(a) 
Design and comparison of performance of DFIG based wind turbine with PID controller, FUZZY Controller, Artificial Neural Network and Model Predictive Controller

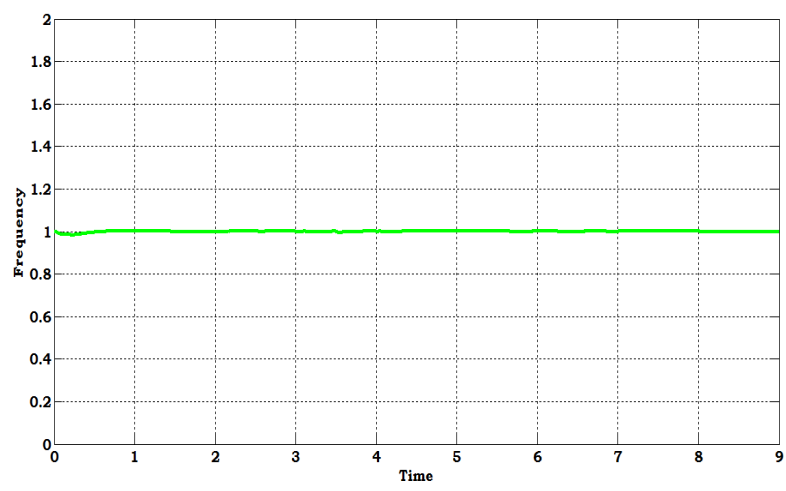

(b)

Figure 15. (a). DC link voltage, (b).Frequency

(ii). Artificial Neural Network (ANN) Based System Test Case 1: When operating system in grid connected mode with battery

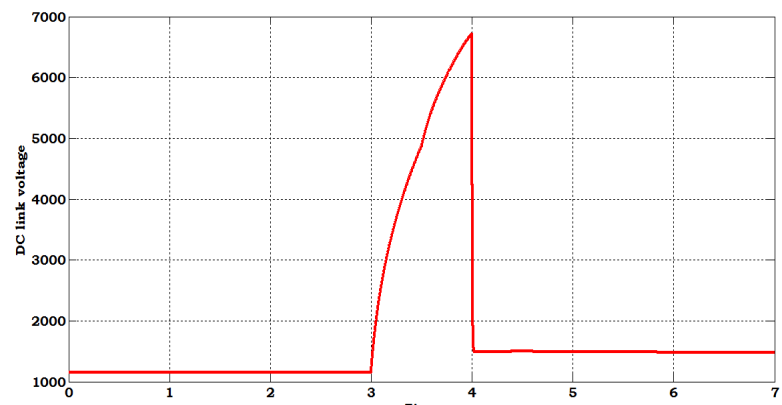

(a)

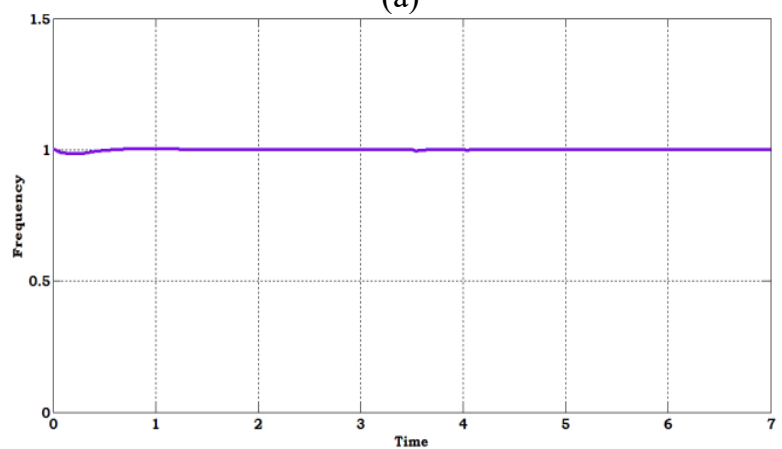

(b)

Figure 16. (a). DC link voltage, (b).Frequency Test Case 2: When operating system in grid connected mode with sudden disconnection of battery

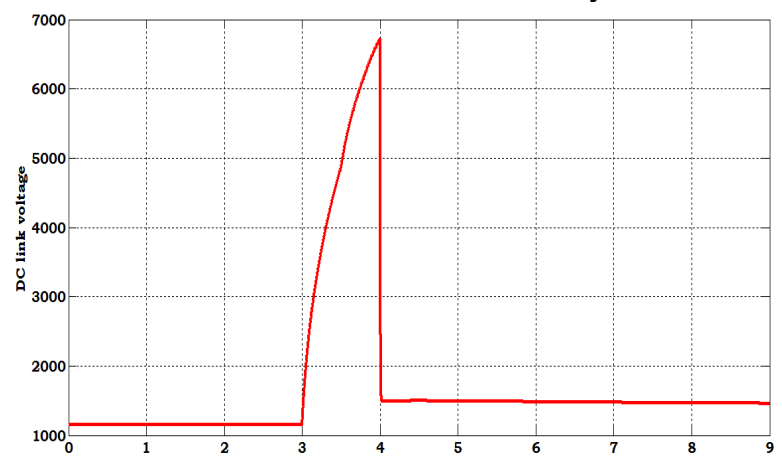

(a)

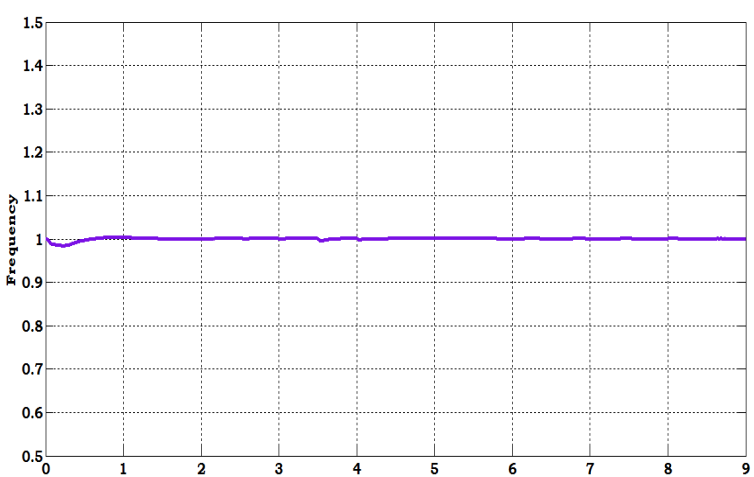

(b)

Figure 17. (a). DC link voltage, (b).Frequency

There is sudden change in DC link voltage at $\mathrm{t}=3 \mathrm{sec}$ but controller brings back voltage and frequency in constant. Test Case 3: when operating system in grid connected mode with sudden connection of other units.

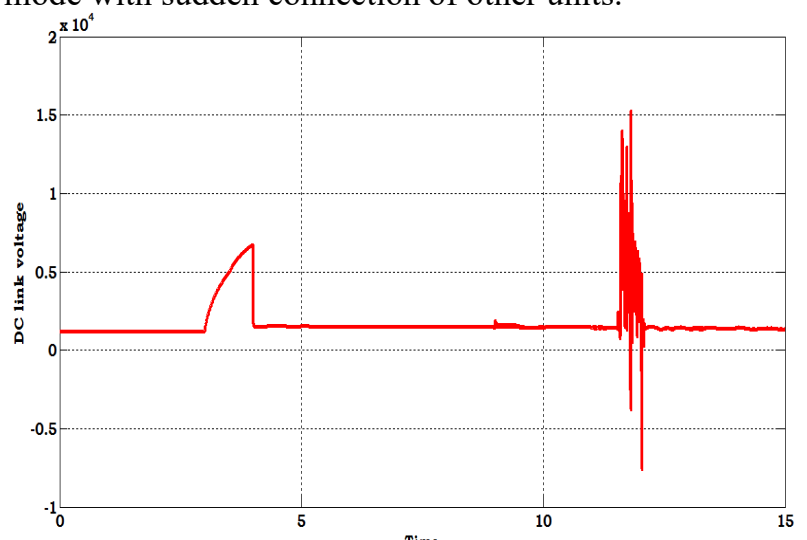

(a)

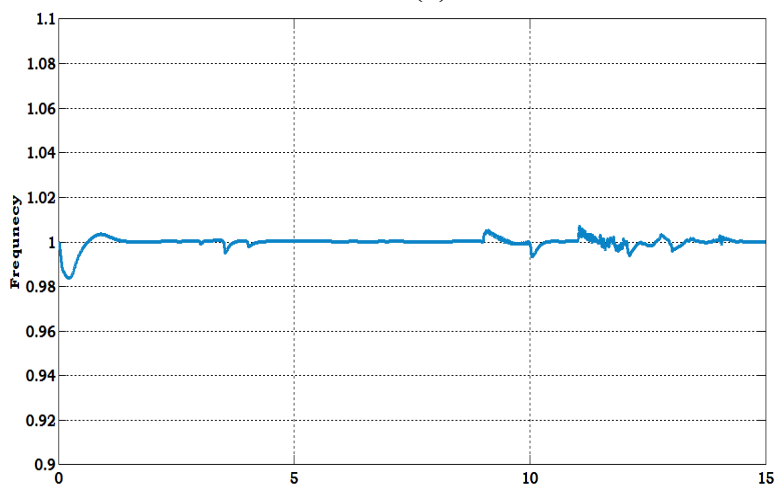

(b)

Figure 18. (a). DC link voltage, (b).Frequency

Other units are suddenly connected at $\mathrm{t}=12 \mathrm{sec}$, hence small disturbance observed in DC link voltage but controller brought back voltage in accurate constant value and frequency also maintained with in the limit perfectly. Test Case 4: When operating system in grid connected mode with sudden fault. 


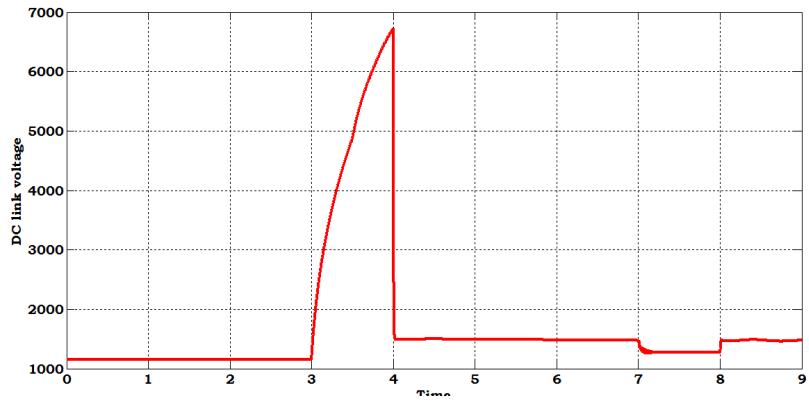

(a)

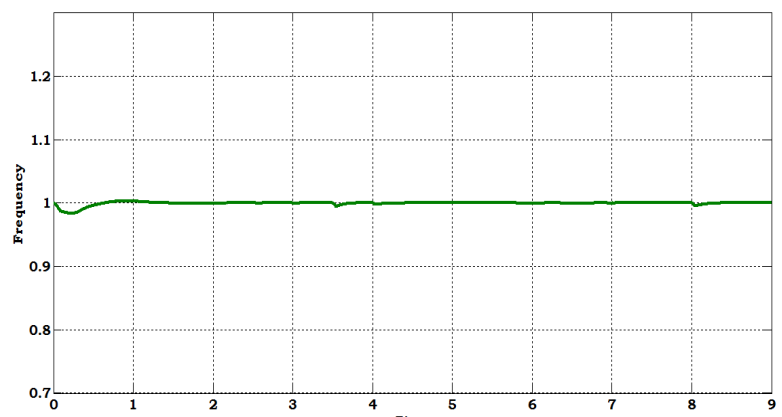

(b)

Figure 19. (a). DC link voltage, (b).Frequency

Sudden transient occurred at $\mathrm{t}=3 \mathrm{sec}$ to $4 \mathrm{sec}$ and fault occurred at $\mathrm{t}=7$ sec but still controller is maintaining constant DC link voltage and frequency.

Test Case 5: When operating system in islanded mode

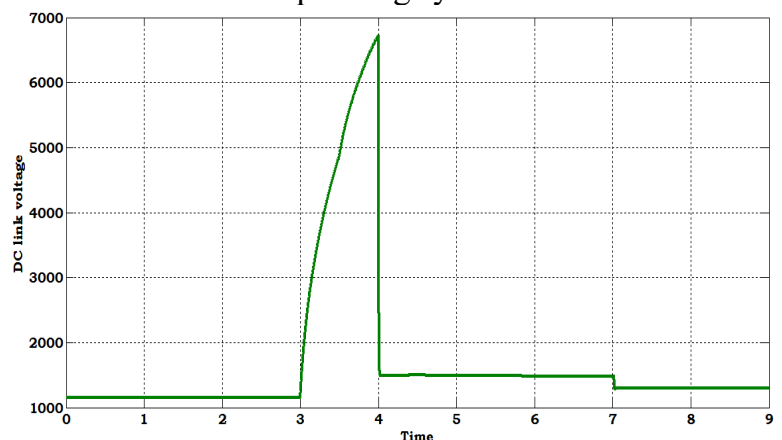

(a)

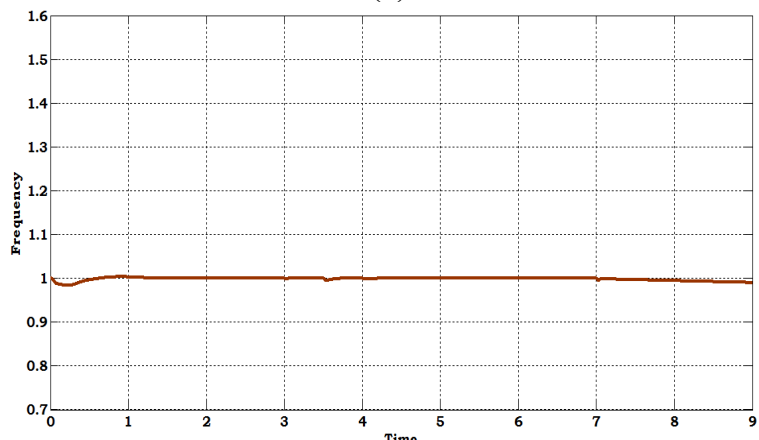

(b)

Figure 20. (a). DC link voltage, (b).Frequency Test Case 6: When operating system in islanded mode with sudden connection of other units

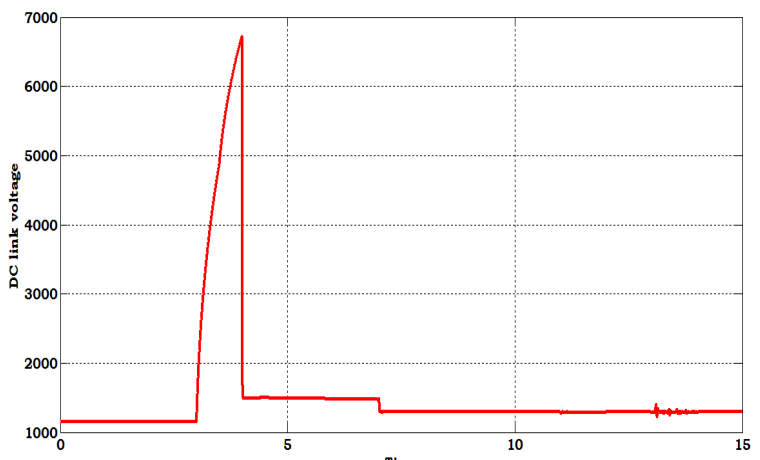

(a)

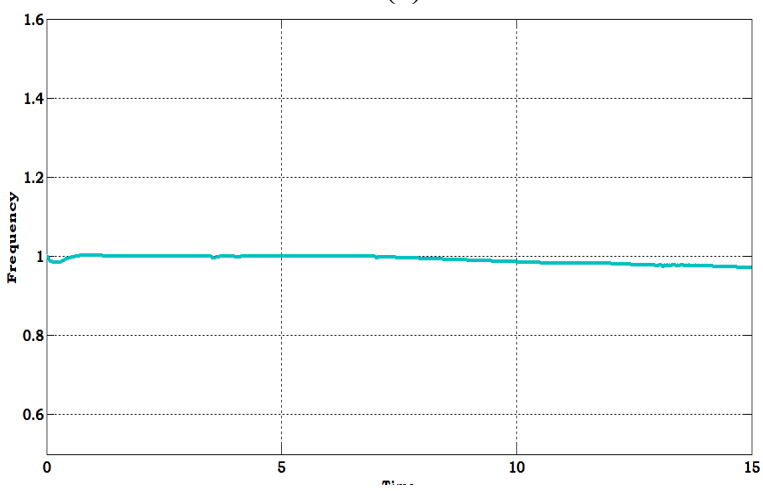

(b)

Figure 21. (a). DC link voltage, (b).Frequency Test Case 7: When operating system in islanded mode with sudden fault

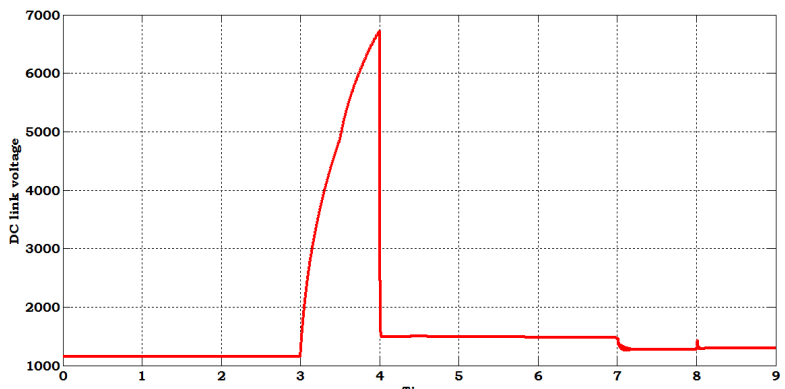

(a)

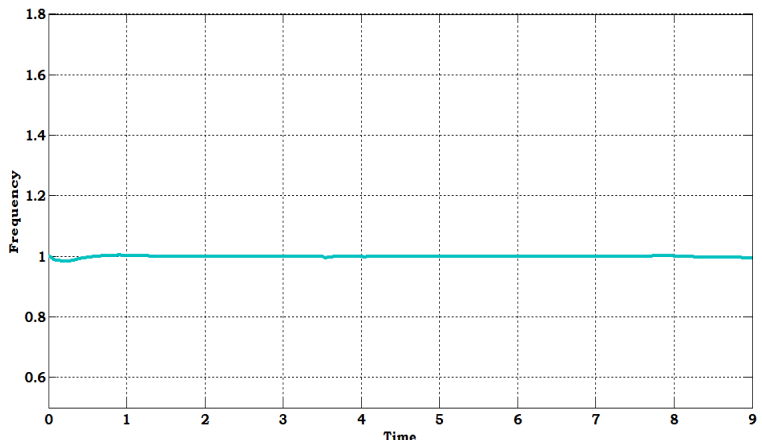

(b)

Figure 22. (a). DC link voltage, (b).Frequency

(iii). Model Predictive Control Based System Test Case 1: When operating system in grid connected mode with battery 
Design and comparison of performance of DFIG based wind turbine with PID controller, FUZZY Controller, Artificial Neural Network and Model Predictive Controller

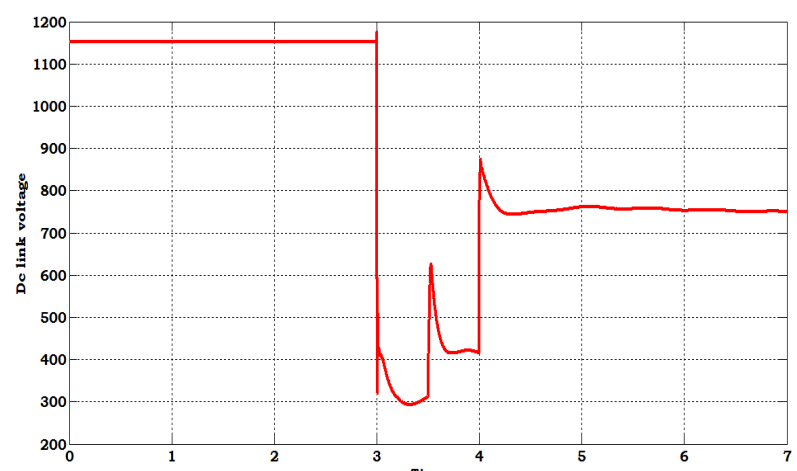

(a)

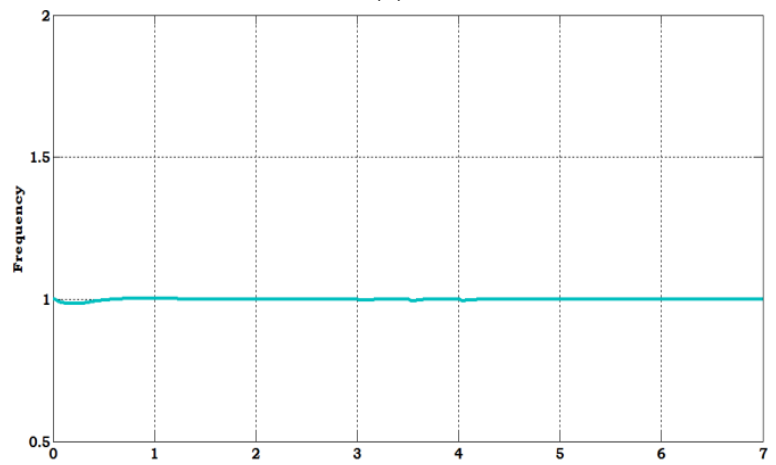

(b)

Figure 23. (a). DC link voltage, (b).Frequency Test Case 2: When operating system in grid connected mode with sudden disconnection of battery

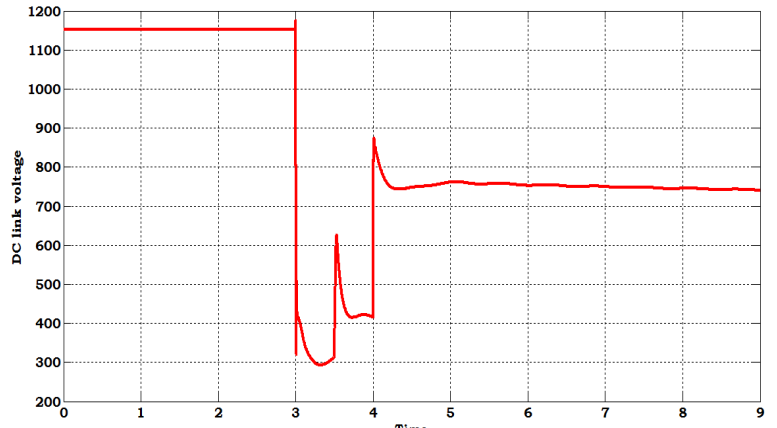

(a)

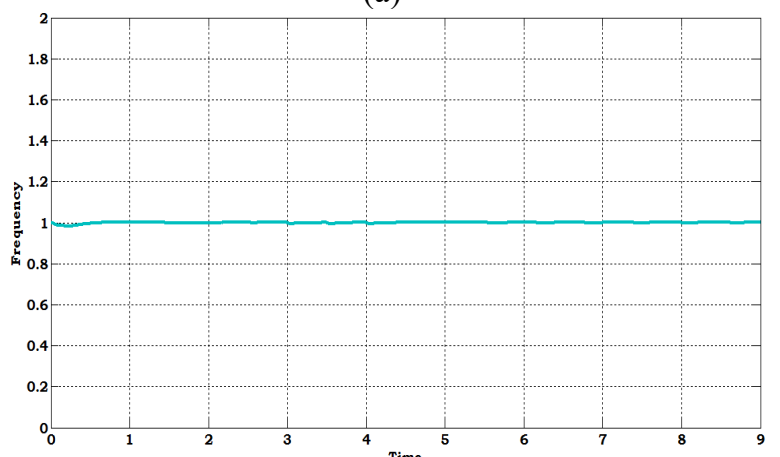

(b)

Figure 24. (a). DC link voltage, (b).Frequency There is sudden change in DC link voltage at $t=3 \mathrm{sec}$ but controller brings back voltage and frequency in constant. Test Case 3: when operating system in grid connected mode with sudden connection of other units.

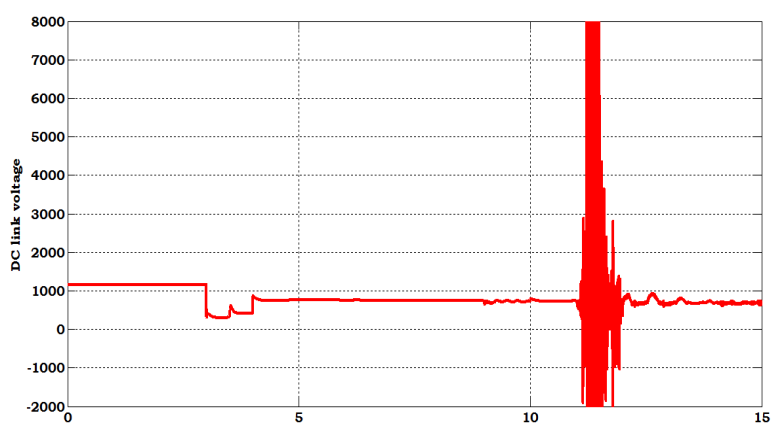

(a)

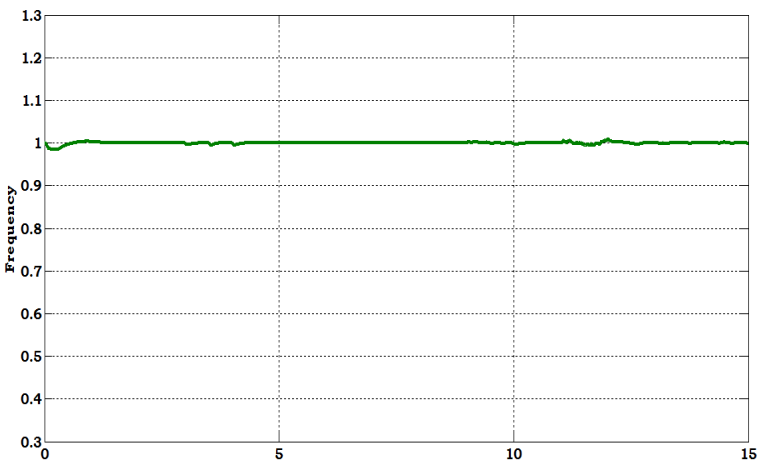

(b)

Figure 25. (a). DC link voltage, (b).Frequency

Other units are suddenly connected at $\mathrm{t}=12 \mathrm{sec}$, hence small disturbance observed in DC link voltage but controller brought back voltage in accurate constant value and frequency also maintained with in the limit perfectly. Test Case 4: When operating system in grid connected mode with sudden fault.

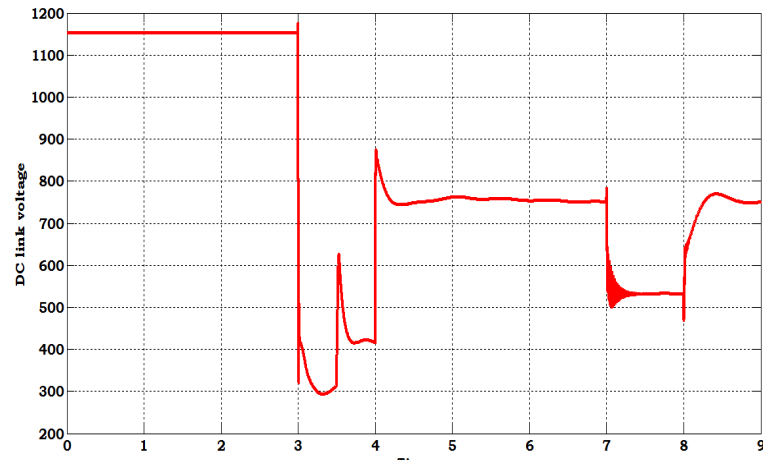

(a)

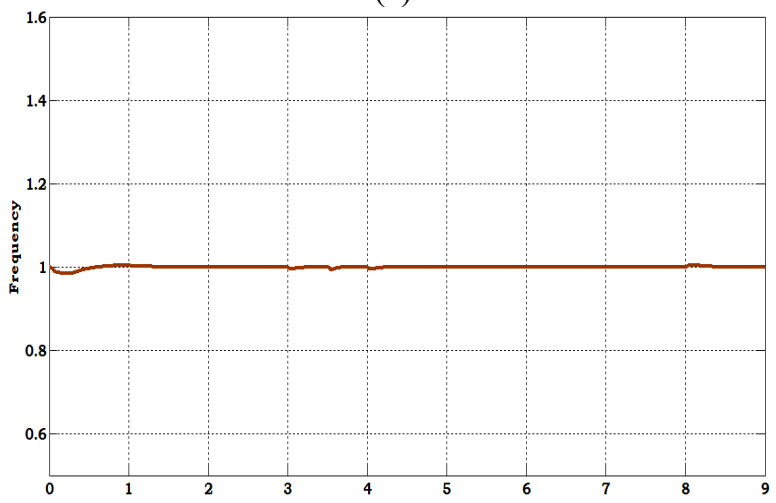

(b)

Figure 26. (a). DC link voltage, (b).Frequency 
Sudden transient occurred at $\mathrm{t}=3 \mathrm{sec}$ to $4 \mathrm{sec}$ and fault occurred at $\mathrm{t}=7 \mathrm{sec}$ but still controller is maintaining constant DC link voltage and frequency.

Test Case 5: When operating system in islanded mode

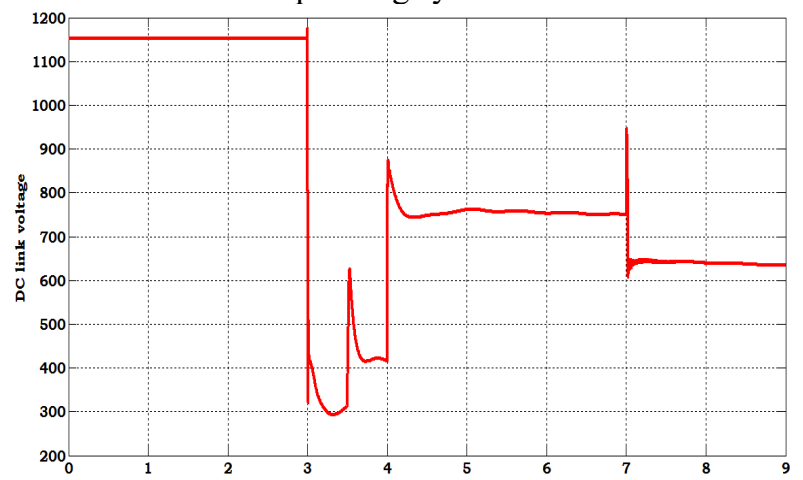

(a)

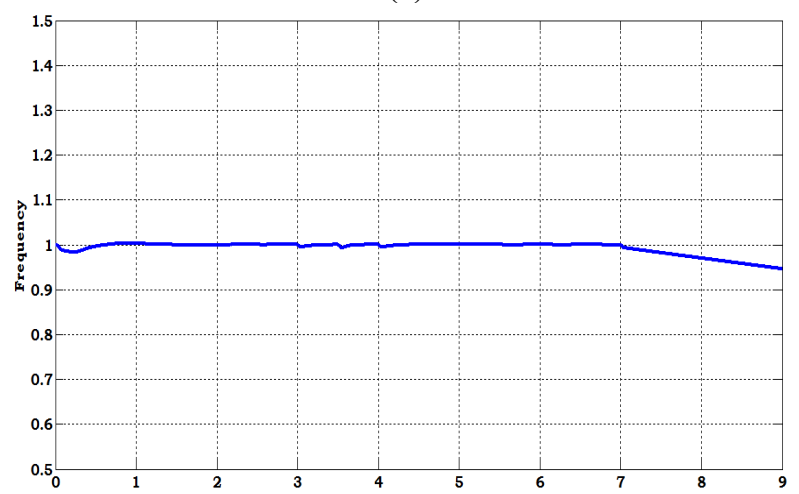

(b)

Figure 27. (a). DC link voltage, (b).Frequency Test Case 6: When operating system in islanded mode with sudden connection of other units

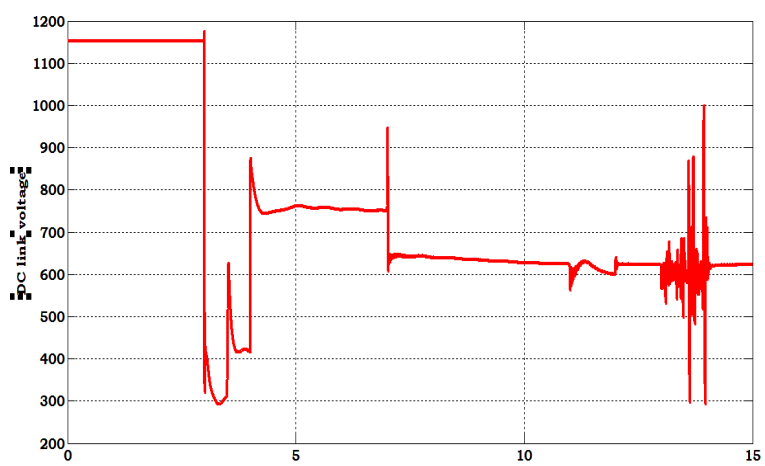

(a)

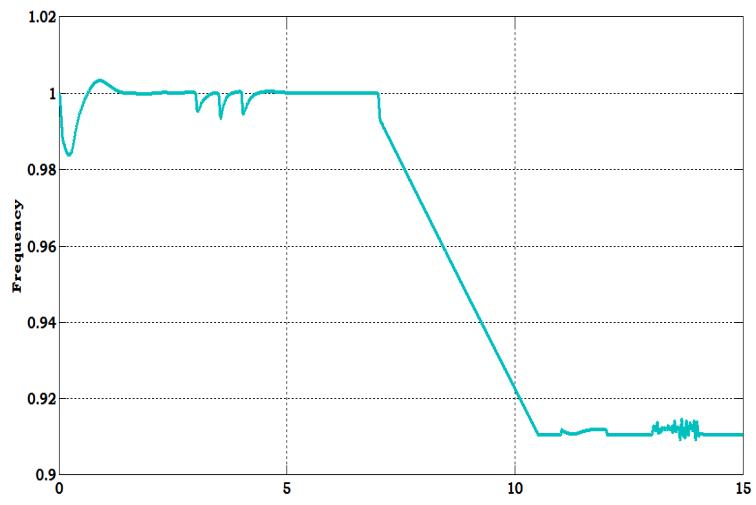

(b)

Figure 28. (a). DC link voltage, (b).Frequency Test Case 7: When operating system in islanded mode with sudden fault

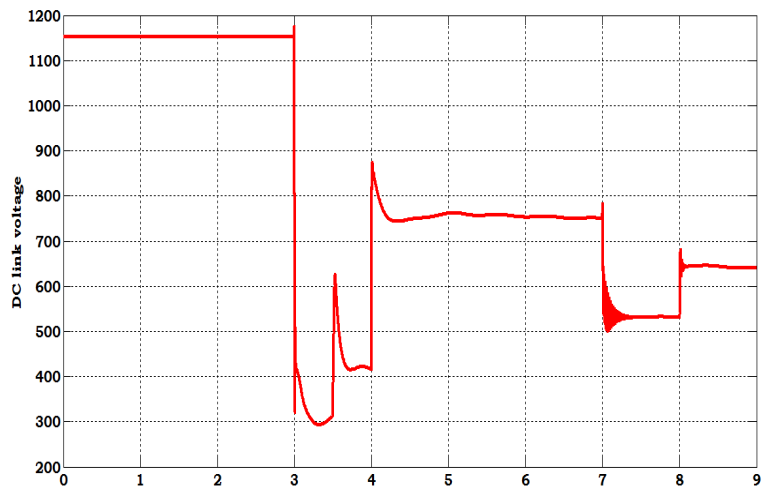

(a)

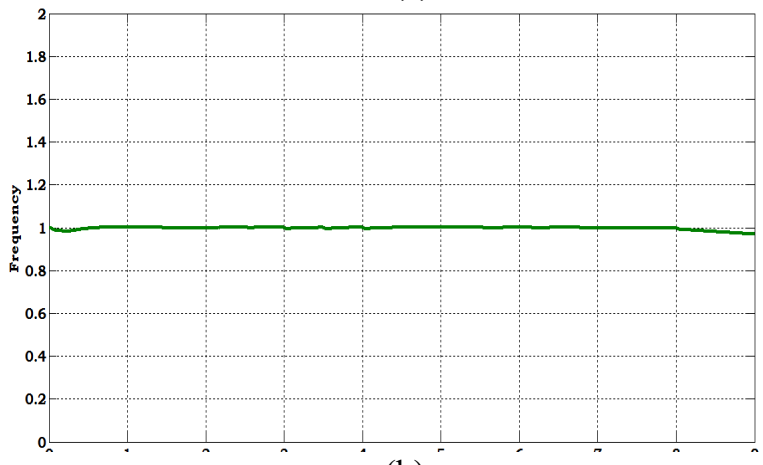

(b)

Figure 29. (a). DC link voltage, (b).Frequency

Table 2. Comparison of Fuzzy logic controller, ANN, MPC controllers

\begin{tabular}{|c|l|l|l|}
\hline Test Case No. & \multicolumn{1}{|c|}{ Fuzzy } & \multicolumn{1}{c|}{ ANN } & MPC \\
\hline Case 1 & $\begin{array}{l}\text { VDC-constant } \\
\text { Freq- constant }\end{array}$ & $\begin{array}{l}\text { VDC-constant } \\
\text { Freq- constant }\end{array}$ & $\begin{array}{l}\text { VDC-constant } \\
\text { Freq- constant }\end{array}$ \\
\hline Case 2 & $\begin{array}{l}\text { VDC-constant } \\
\text { Freq- constant }\end{array}$ & $\begin{array}{l}\text { VDC-constant } \\
\text { Freq- constant }\end{array}$ & $\begin{array}{l}\text { VDC-constant } \\
\text { Freq- constant }\end{array}$ \\
\hline
\end{tabular}


Design and comparison of performance of DFIG based wind turbine with PID controller, FUZZY Controller, Artificial Neural Network and Model Predictive Controller

\begin{tabular}{|c|l|l|l|}
\hline Case 3 & $\begin{array}{l}\text { VDC-oscillations } \\
\text { Freq- oscillations }\end{array}$ & $\begin{array}{l}\text { VDC-oscillations } \\
\text { Freq- oscillations }\end{array}$ & $\begin{array}{l}\text { VDC-oscillations } \\
\text { Freq- oscillations }\end{array}$ \\
\hline Case 4 & $\begin{array}{l}\text { VDC- decrease } \\
\text { Freq- decrease }\end{array}$ & $\begin{array}{l}\text { VDC- decrease } \\
\text { Freq- decrease }\end{array}$ & $\begin{array}{l}\text { VDC- constant } \\
\text { Freq- constant }\end{array}$ \\
\hline Case 5 & $\begin{array}{l}\text { VDC- decrease } \\
\text { Freq- decrease }\end{array}$ & $\begin{array}{l}\text { VDC- decrease } \\
\text { Freq- decrease }\end{array}$ & $\begin{array}{l}\text { VDC- constant } \\
\text { Freq- constant }\end{array}$ \\
\hline Case 6 & $\begin{array}{l}\text { VDC-fluctuations } \\
\text { Freq- fluctuations }\end{array}$ & $\begin{array}{l}\text { VDC- decrease } \\
\text { Freq- decrease }\end{array}$ & $\begin{array}{l}\text { VDC-fluctuations } \\
\text { Freq- fluctuations }\end{array}$ \\
\hline Case 7 & $\begin{array}{l}\text { VDC- decrease } \\
\text { Freq- decrease }\end{array}$ & $\begin{array}{l}\text { VDC- decrease } \\
\text { Freq- decrease }\end{array}$ & Freq- constant \\
\hline
\end{tabular}

From the comparison table 2 , it can be concluded that the various test cases performed on fuzzy controller, ANN controller and MPC controller. But table 2 shows MPC has the better performance in terms of frequency among the other two controllers for all the cases. By MPC most of DC link voltage and frequency maintained constant.

Table 3. Specifications of the DFIG system

\begin{tabular}{|c|l|l|}
\hline S. No. & \multicolumn{1}{|c|}{ Parameter } & \multicolumn{1}{c|}{ Value } \\
\hline 1 & DC link voltage & $1150 \mathrm{~V}$ \\
\hline 2 & DC link capacitor & $10000 \mathrm{uF}$ \\
\hline 3 & Wind speed & $10 \mathrm{~m} / \mathrm{s}$ \\
\hline 4 & Grid nominal voltage & $120 \mathrm{KV}$ \\
\hline 5 & DFIG rated voltage & $575 \mathrm{~V}$ \\
\hline
\end{tabular}

Table 4. Specifications of the RL load

\begin{tabular}{|c|l|c|}
\hline S. No. & \multicolumn{1}{|c|}{ Parameter } & Value \\
\hline 1 & Active power & $10 \mathrm{e} 6$ \\
\hline 2 & Inductive reactive power & $100 \mathrm{e} 3$ \\
\hline 3 & $\begin{array}{l}\text { Capacitive reactive } \\
\text { power }\end{array}$ & $100 \mathrm{e} 3$ \\
\hline 4 & Nominal voltage & $25 \mathrm{e} 3$ \\
\hline 5 & frequency & $60 \mathrm{~Hz}$ \\
\hline
\end{tabular}

Table 5. Specifications of the induction generator

\begin{tabular}{|c|l|c|}
\hline S. No. & \multicolumn{1}{|c|}{ Parameter } & Value \\
\hline 1 & Nominal power & $6 \mathrm{e} 6$ \\
\hline 2 & Nominal voltage & 575 \\
\hline 3 & Frequency & $60 \mathrm{~Hz}$ \\
\hline
\end{tabular}

Table 6. Specifications of the PV sys and induction motor

\begin{tabular}{|c|l|c|}
\hline S. No. & \multicolumn{1}{|c|}{ Parameter } & Value \\
\hline 1 & $\begin{array}{l}\text { Rated voltage of PV } \\
\text { system }\end{array}$ & $560 \mathrm{~V}$ \\
\hline 2 & Nominal power & 3730 \\
\hline 3. & Nominal voltage & 460 \\
\hline
\end{tabular}

\section{Conclusion}

The design of multimode droop control strategy based variable speed wind power generation system has been designed in this paper. The multi mode droop control strategy has been designed which enhanced the system to operate in connection with the grid system and also in the standalone mode of operation. The multi mode control strategy employing the DC link voltage controller has been designed to control the DC link capacitor voltage for operating the grid side converter and current controller to control current and torque of the rotor side converter. The control strategy has been analysed with the conventional controller like PI controller, intelligent controllers like Fuzzy controller, artificial neural network (ANN) and model predictive controller (MPC) which predicts the future variables. A comparison has been performed with the above mentioned different types of controllers based wind power generation system in terms of different parameters with different test cases and finally concluded that MPC fed DFIG base wind energy unit provides better control of the system compared to the other controllers. The analysis of different test cases with different controllers and verification of results has been performed using MATLAB 2013a 


\section{References}

[1] Faruk A. Bhuiyan, Amirnaser Yazdani, "Multimode Control of a DFIG-Based Wind-Power Unit for Remote Applications", IEEE transactions on power delivery, Vol.24, No.4, pp.2079-2089, 2009.

[2] Akira Kaneko, Naoyuki Hara, Keiji Konishi, "Model predictive control of DFIG-based wind turbines", 2012 American Control Conference,2012.

[3] Sakina Elkhadiri, Pr.Lamiaa Elmenzhi, Pr.Abdelouahid Lyhyaoui, "Fuzzy Logic Control of DFIG-based Wind Turbine", 2018 International Conference on Intelligent Systems and Computer Vision, 2018.

[4] Tine Vandoorn, Bart Meersman, Jeroen Kooning and Lieven Vandevelde, "Analogy between conventional grid control and Islanded micro grid control based on a global dc-link voltage droop, 2012 IEEE transactions on power Delivery, Vol.27, No.3, pp.1405-1414.

[5] M. Siva Kumar, G.N.S Vaibhav, "Droop Control in DFIG-Based Wind Turbines Implementation and its Analysis and Impacts on Micro grid Stability", International Journal of Advanced Research in Electrical, Electronics and Instrumentation Engineering", Vol. 6, No.1, pp.156-164, 2017.

[6] B.Mansoor,P.Shashavali, M.Khaimulla, "Implementation of Droop Control in Doubly Fed Induction Generator Based Wind Turbines", International Journal of Advanced Research in Electrical, Electronics and Instrumentation Engineering,Vol.5, No.8, pp.202-211, 2016.

[7] Leiqi Zhang, Jiazuo Hou, H uanhai Xin, Zhen wang, Deqiang Gan, "Maximum power estimation and droop control of DFIG based wind turbines in multi mode microgrids",2014 IEEE PES Asia pacific power and energy engineering, pp.1-6,2014.

[8] P. Mukherjee and V. V. Rao, "Fuzzy Logic Controlled Superconducting Magnetic Energy Storage for Leveling Power Fluctuation of Grid Connected Wind Generator," 2018 International Conference on Power Energy, Environment and Intelligent Control (PEEIC), Greater Noida, India, 2018, pp. 665-669. doi: 10.1109/PEEIC.2018.8665563

[9] Feng Zhang et al., "Battery ESS planning for wind smoothing via variable-interval reference modulation and self-adaptive SOC control strategy", IEEE Transactions on Sustainable Energy, Vol. 8, No. 2, April 2017.

[10] S. Zhang, Y. Mishra and M. Shahidehpour, "Fuzzy-Logic Based Frequency Controller for Wind Farms Augmented With Energy Storage Systems," in IEEE Transactions on Power Systems, Vol. 31, No.2, pp.1595-1603, March2016.doi: 10.1109/TPWRS.2015.2432113

[11] C. D. Das, A. K. Roy, N. Shinha, "GA based frequency controller for solar thermal diesel wind hybrid energy generation energy storage system", Int. J. Elect. Power Energy Syst., Vol. 43, No. 1, pp. 262-279, 2012.

[12] A. Esmaili, "A hybrid system of Li-lon capacitors and flow battery for dynamic wind energy support", IEEE Trans. Ind. Appl., Vol. 49, No. 4, pp. 1649-1657, Jul.Aug. 2013.

[13] V. Sheeja, P. Jaya prakash, B. Singh and R. Uma, "Neural network theory based voltage and frequency controller for standalone wind energy conversion system," 2010 Joint International Conference on Power
Electronics, Drives and Energy Systems \& 2010 Power India, New Delhi, 2010, pp.1-6. doi: 10.1109/PEDES.2010.5712544

[14] Tawfek K. Mahmoud, Zhao Yang Dong, Jin Ma, "A Developed Integrated Scheme Based Approach for Wind Turbine Intelligent Control", Sustainable Energy IEEE Transactions on, Vol. 8, No. 3, pp. 927-937, 2017.

[15] A. Mesemanolis and C. Mademlis, "A Neural Network based MPPT controller for variable speed Wind Energy Conversion Systems," 8th Mediterranean Conference on Power Generation, Transmission, Distribution and Energy Conversion (MEDPOWER 2012), Cagliari, 2012, pp. 1-6. doi: 10.1049/cp.2012.2034.

[16] C. Hong, W. Lin and F. Cheng, "Application of Fuzzy Neural Network Sliding Mode Controller for Wind Driven Induction Generator System," 2007 International Conference on Intelligent Systems Applications to Power Systems, Toki Messe, Niigata, 2007, pp. 1-6. doi: 10.1109/ISAP.2007.4441646

[17] B. M. Zaineb, A. Aicha, B. H. Mouna and S. Lassaad, "Speed control of DC motor based on an adaptive feed forward neural IMC controller," 2017 International Conference on Green Energy Conversion Systems (GECS), Hammamet, 2017, pp. 1-7. doi: 10.1109/GECS.2017.8066278

[18] J. S. Thongam, P. Bouchard, R. Beguenane and I. Fofana, "Neural network based wind speed sensorless MPPT controller for variable speed wind energy conversion systems," 2010 IEEE Electrical Power \& Energy Conference, Halifax, NS, 2010, pp.1-6. doi: 10.1109/EPEC.2010.5697221

[19] S. Messalti, B. Boudjellal and A. Said, "Artificial neural networks controller for power system voltage improvement," IREC2015The Sixth International Renewable Energy Congress, Sousse, 2015, pp.1-6. doi: 10.1109/IREC.2015.7110897

[20] S. Messalti, S. Belkhiat, S. Saadate, D. Flieller, "Improvement of Power System Transient Stability Using TCBR and TCSC A Comparative study", International Review of Electrical Engineering, vol. 5, no. 6, pp. 2727-2736, 2010.

[21] Y. Shi, X. Xiang, Y. Zhang and D. Sun, "Design of stochastic model predictive control for wind energy conversion system," 2017 International Workshop on Complex Systems and Networks (IWCSN), Doha, 2017, pp.108-114.doi: 10.1109/IWCSN.2017.8276513

[22] isitpol Chirapongsananurak and Naebboon Hoonchareon, "Design of a controller for DFIG-based wind power generation using model predictive control," ECTI-CON2010: The 2010 ECTI International Conference on Electrical Engineering/Electronics, Computer, Telecommunications and Information Technology, Chiang Mai, 2010, pp. 833-837.

[23] M. Khalid and A. V. Savkin, "Model predictive control for wind power generation smoothing with controlled battery storage," Proceedings of the 48th IEEE Conference on Decision and Control (CDC) held jointly with 2009 28th Chinese Control Conference, Shanghai, 2009, pp. 7849-7853.doi: 10.1109/CDC.2009.5400002

[24] K Naresh, P. Umapathi Reddy, P. Sujatha, "Analysis and performance comparison of multimode control scheme based doubly fed induction generator wind power unit with PMSG wind power unit", Journal of Green Engineering, Volume-10, Issue-10, October 2020, pp. 9328-9347. 